\title{
Formulation of Tablets Containing Glimepiride-loaded Mesoporous Silica Particles
}

\author{
CH. TCH. VOYCHEVA*, B. TZANKOV, D. G. TZANKOVA', K. I. AVRAMOVA² AND K. P. YONCHEVA \\ Department of Pharmaceutical Technology and Biopharmacy, ${ }^{1}$ Department of Pharmaceutical Chemistry, Faculty of Pharmacy, \\ Medical University of Sofia, 1000 Sofia, ${ }^{2}$ Institute of Physical Chemistry, Bulgarian Academy of Science, 1113 Sofia, Bulgaria
}

\section{Voycheva et al.: Tablets Containing Glimepiride-loaded Mesoporous Silica Particles}

\begin{abstract}
The aim of the present study was to develop a tablet formulation with improved dissolution of glimepiride. Glimepiride was loaded into two types of mesoporous silica particles via solvent-incubation method. Physicochemical characterization of the particles was carried out by transmission electron microscopy, infrared spectroscopy, dynamic light scattering and thermogravimetric analysis. Flowability and compressibility characteristics of the powder mixtures, containing pure glimepiride as well as both types of drug-loaded silica particles and excipients were evaluated by bulk and tapped density and angle of repose. Tablets were prepared by direct compression method and consequently tested for hardness, friability, disintegration and in vitro release properties. In vitro release studies demonstrated that the glimepiride dissolution rate was notably improved from tablets prepared with both types mesoporous silica particles as compared with the bulk drug.
\end{abstract}

Key words: Mesoporous silica particles, MCM-41, HMS, poorly water-soluble drug, glimepiride

Glimepiride, chemically 1-(p-(2-(3-ethyle-4-methyl2-oxo-3-pyrroline-1-carboxamido)ethyl)phenyl) sulfonyl)-3-(trans-4-methylcyclohexyl) is a third generation hypoglycemic sulfonylurea used in the treatment of non-insulin-dependent diabetes mellitus ${ }^{[1]}$. Glimepiride is a class II drugs according to the biopharmaceutical classification system. This class of drugs typically exhibit variable absorption from gastrointestinal tract due to their low solubility in GI fluids. Despite their good permeability these drugs show low $\mathrm{pH}$-dependent solubility, which may cause poor dissolution and unpredicted bioavailability ${ }^{[2,3]}$. Oral absorption of glimepiride is dissolution rate limited, therefore it displays erratic oral bioavailability, which can lead to irreproducible clinical response or in some cases therapeutic failure ${ }^{[4-6]}$. These properties of glimepiride give rise to difficulties in the design of pharmaceutical formulations and led to variable oral bioavailability ${ }^{[7,8]}$. In this view, different methods were applied aiming to improve water solubility of glimepiride, e.g. inclusion complexes with cyclodextrins, solid dispersions using either water soluble $^{[9]}$ or insoluble carriers ${ }^{[10,11]}$.

Mesoporous silica materials (MSM) have been used as a potential drug delivery carrier for poorly soluble

*Address for correspondence

E-mail: hrisky@gmail.com

May-June 2019 $\operatorname{drugs}^{[12]}$. Their attractive characteristics are high surface area, large pore volume, tunable pore size, narrow distribution, good biocompatibility and chemical inertness. Some of these characteristics are related with the opportunity to improve oral bioavailability of poorly soluble drugs via improved drug dissolution rate ${ }^{[13-16]}$. Loading of poorly water soluble drugs into the pores of mesoporous silica restricts their crystallization and improves drug dissolution from the materials compared to the bulk drug molecules ${ }^{[12]}$. The aim of this study was to prepare and characterize tablets with improved dissolution properties of glimepiride, based on MCM41 and hexagonal mesoporous silica (HMS) materials. The formulation of glimepiride-loaded mesoporous silica in tablets could combine high chemical and physical stability and reproducible release behaviour.

\section{MATERIALS AND METHODS}

Mesoporous silica MCM-41 type (hexagonal)

This is an open access article distributed under the terms of the Creative Commons Attribution-NonCommercial-ShareAlike 3.0 License, which allows others to remix, tweak, and build upon the work non-commercially, as long as the author is credited and the new creations are licensed under the identical terms

Accepted 05 April 2019

Revised 14 Deceember 2018

Received 31 September 2018

Indian J Pharm Sci 2019;81(3):483-488 
with defined characteristics (average pore size $2.6 \mathrm{~nm}$, surface area $1003 \mathrm{~m}^{2} / \mathrm{g}$ and free volume $1.07 \mathrm{~cm}^{3} / \mathrm{g}$ ) and HMS (average pore size $3.3 \mathrm{~nm}$, surface area $880 \mathrm{~m}^{2} / \mathrm{g}$ and free volume $1.28 \mathrm{~cm}^{3} / \mathrm{g}$ ) were purchased from Sigma-Aldrich (St. Louis, USA). Glimepiride, dichloromethane, ethanol, disodium hydrogen phosphate dihydrate, potassium dihydrogen phosphate were also supplied from SigmaAldrich. Microcrystalline cellulose (Avicel PH 102), colloidal silicon dioxide (Aerosil), Mg stearate and croscarmellose were purchased from BASF (Germany). Deionized water was prepared by ion exchange.

\section{Glimepiride loading on the mesoporous particles ${ }^{[17]}$ :}

Glimepiride (100 mg) was dissolved in $8 \mathrm{ml}$ of dichloromethane. Then $100 \mathrm{mg}$ particles (MCM-41 or HMS) preheated for $1 \mathrm{~h}$ at $120^{\circ}$ were added to the glimepiride solution. The mixture was incubated at $37^{\circ}$ with permanent stirring $(180 \mathrm{rpm})$. Whereafter, $25 \mathrm{ml}$ of ethanol were added and the dichloromethane was removed by vacuum distillation. The procedure continued with addition of water and extraction of ethanol. Finally, the dispersion was filtered through a $0.1 \mu \mathrm{m}$ membrane filter, washed with ethanol and dried in a vacuum desiccator for $24 \mathrm{~h}$.

\section{Characterization of MCM-41 and HMS particles:}

The porous structure of the samples was characterized using a transmission electron microscopy (TEM, Jeol JEM 2100 HR STEM, 200KV; point-resolution $0.23 \mathrm{~nm}$ ). Attenuated total reflection infrared spectra were recorded by spectrometer Nicolette 400 . The IR spectra, in absorbance mode, were obtained over the spectral region from 400 to $4000 \mathrm{~cm}^{-1}$.

Determinations of nanoparticle size, polydispersity index (PI) and zeta potential were performed using a Zetasizer (Malvern Instruments, Worcestershire, UK). The samples were dispersed in deionized water and measured at a scattering angle of $90^{\circ}$ and $25^{\circ}$. The measurements were made in triplicate. Thermo gravimetric analysis (TGA) was performed using a TGA-50 instrument (Shimadzu, Japan) at a heating rate of $10^{\circ} / \mathrm{min}$ under a nitrogen purge of $40 \mathrm{ml} / \mathrm{min}$.

\section{Characterization of powder mixture:}

Bulk and tapped densities of the powdered mixtures, were determined using a taped density tester Erweka type SVM20. The values were used for calculation of Carr index and Hausner ratio. Angle of repose of the different tableting mixtures was determined using
Powder Flow Analyzer Pharma test Sartorius type Ptger.

\section{Preparation and characterization of tablets:}

The composition of tablets containing pure glimepiride or glimepiride-loaded mesoporous silica nanoparticles is presented in Table 1. The mixture of respective nanoparticles and the excipients were directly compressed using a single punch tablet press (Erweka AR401, Germany) equipped with a $9 \mathrm{~mm}$ diameter punches with flat faces. The crushing strength of the tablets was determined as the force $(\mathrm{N})$ needed to break the tablet diametrically (apparatus Erweka TBH 30, Germany). The friability of tablets was determined using a friabilator (Pharma test PTF 20 ER, Germany) at a speed of $25 \mathrm{rpm}$ for $4 \mathrm{~min}$. The percent weight loss was expressed as the tablet friability. Tablet disintegration time was measured according to European Pharmacopoeia with a disintegration tester (Erweka ZT 72, Erweka, Germany). The basket rack assembly was positioned in one litre of $\mathrm{pH} 6.8$ phosphate buffer at $37 \pm 2^{\circ}$. The time taken for complete disintegration of the tablet with no palpable mass remaining in the apparatus was measured in minutes.

\section{In vitro release studies:}

For the in vitro release studies, tablets containing $2 \mathrm{mg}$ glimepiride (pure or loaded into MCM-41 and HMS particles) were incubated in $900 \mathrm{ml}$ phosphate buffer with $\mathrm{pH}$-value of 6 and 8 . Sodium lauryl sulfate (2\%) was added to the medium. The dissolution tests were performed by paddle method with a stirring rate of $100 \mathrm{rpm}$ at $37^{\circ}$ (Copley Scientific DIS 8000, type NE6COPD). Samples were withdrawn at appropriate time intervals and replaced by fresh buffer. The samples collected were centrifuged at $15000 \mathrm{rpm}$ for $15 \mathrm{~min}$ and the concentration of the released glimepiride was determined using UV-spectrophotometry at a

TABLE 1: COMPOSITION OF TABLETS

\begin{tabular}{lccc}
\hline Sample & I & II & III \\
\hline Glimepiride & 4 & - & - \\
Glimepiride-MCM & - & 8.78 & - \\
Glimepiride-HMS & - & - & 6.2 \\
Avicel PH102 & 90 & 85.22 & 87.8 \\
Talc & 1 & 1 & 1 \\
Mg stearate & 1 & 1 & 1 \\
Croscarmellose & 4 & 4 & 4 \\
Total in mg & 100 & 100 & 100 \\
\hline
\end{tabular}

Pure glimepiride (I), glimepiride-loaded MCM-4l (II) and glimepirideloaded HMS (III) 
wavelength of $230 \mathrm{~nm}$ (Thermo Fisher Scientific EVO300 PC, US).

\section{RESULTS AND DISCUSSION}

TEM were used to determine the particle morphology and structure of the mesoporous materials. As shown in TEM images (fig. 1), MCM-41 with defined hexagonal pores (fig. 1a) had matrix structure while HMS (fig. 1b) had a hollow core and mesoporous shell. Both types of particles exhibit spherical shape. The images presented preserved porous structure after drug-loading for both types of silica particles (fig. 1c and d). No significant changes were observed after drug-loading procedures. This fact confirms literature data for high mechanical stability of mesoporous silica particles, which is prerequisite for further tableting of these particles.
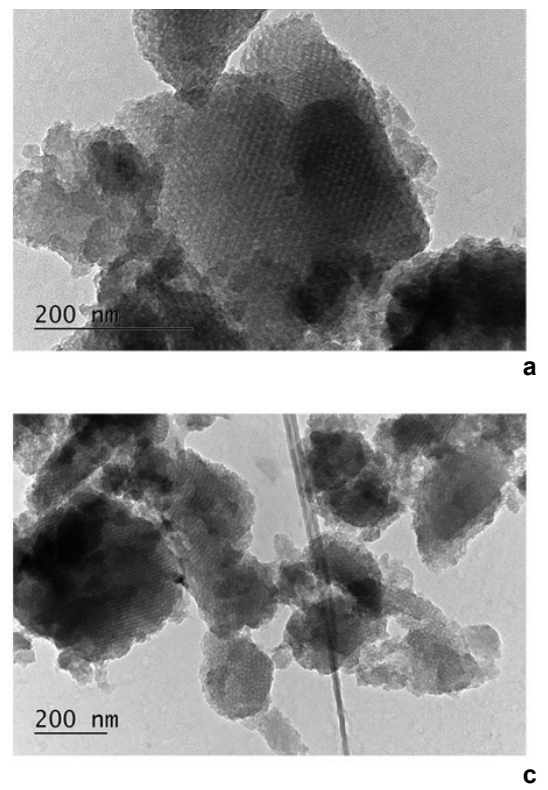

Fig. 1: TEM photographs

Unloaded (a) MCM-41 and (b) HMS and glimepiride-loaded (c) MCM/glimepiride and (d) HMS/glimepiride particles

Fig. 2: Infrared spectra

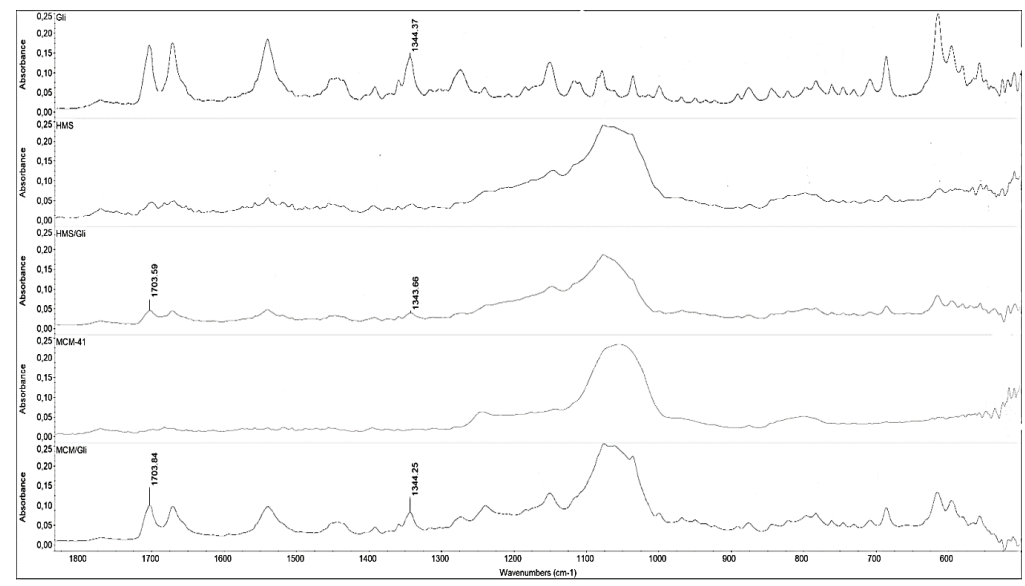

Infrared spectra of pure glimepiride, HMS, HMS/glimepiride, MCM-41 and MCM/glimepiride 
Dynamic light scattering showed an average diameter less than $600 \mathrm{~nm}$ and moderate PI for the pure particles that correlated with TEM observations. The size of the loaded mesoporous silica nanoparticles (fig. 3a) and PI slightly increased after drug loading (fig. 3b). Zetapotential values of both types of mesoporous particles were negative, which is typical for these types of MSM (fig. 3c). The surface charge of MCM-41 and HMS particles was similar and comparable to the results of other authors ${ }^{[19]}$. Slight increase of zeta-potential for glimepiride-loaded particles was observed. However, the change was insignificant and could not be considered as a premise for altered physical stability. The amount of the loaded glimepiride was measured by TG analysis ${ }^{[20,21]}$. Fig. 4 shows the DTA heat flow
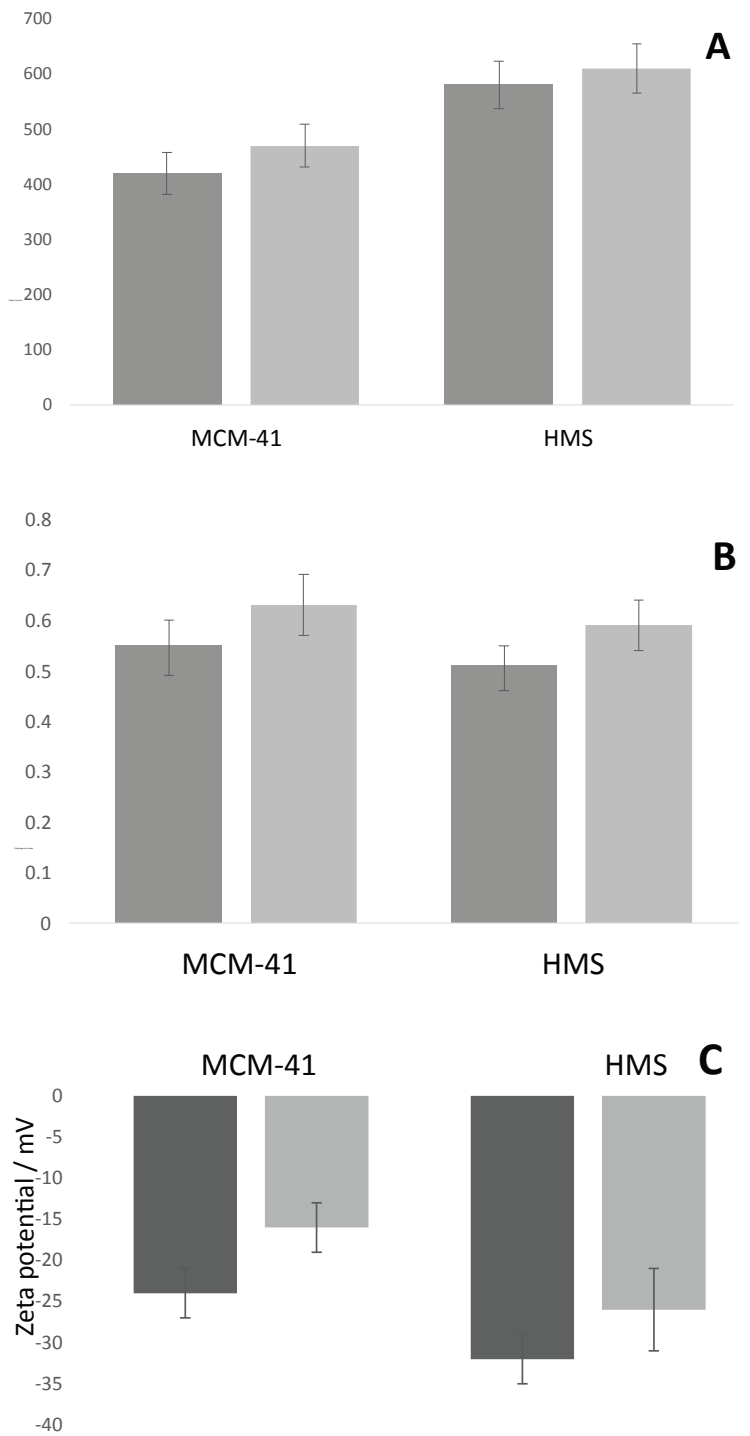

Fig. 3: DLS characteristics

(A) Size, (B) polydispersity index and (C) zeta potential of pure and glimepiride-loaded mesoporous silica particles. Loaded ( $\square$ ) and unloaded ( $\square$ ), mean \pm SD, $n=3$ vs. T curve, denoting the mass loss while heating. The glimepiride weight lost comes to $100 \%$ at temperature interval 500-600 (fig. 4, black curve). At temperatures over $700^{\circ}$ the carriers undergo some weight losses (fig. 4), which probably were connected with structural chances of the carriers. It was found that for MCM41 weight loss was approximately $5 \%$ due to carrier dehydration compared to $2 \%$ for the HMS. Our results showed that at equal conditions MCM-41 can load $45 \%$ glimepiride while for HMS the loading capacity reached $65 \%$. The difference in drug loading can be explained with the different structure of the particles and the higher total free volume of HMS particles $\left(1.28 \mathrm{~cm}^{3} / \mathrm{g}\right.$, compared to $1.07 \mathrm{~cm}^{3} / \mathrm{g}$ for $\mathrm{MCM}-41$ particles).

The flowability and compressibility of the mixtures containing pure of encapsulated glimepiride were studied in order to evaluate the possibility for direct compression. The angle of repose defined for pure glimepiride and the drug loaded MCM and HMS particles indicated poor flowability (Table 2) ) $^{[22]}$. An angle of repose higher than 40 degrees indicates that the powder requires flowability improvement. The calculation of Hausner ratio resulted in values between 1.35 and 1.45 , whichindicated poorflowabilityaccording to USP (Table 2). Thus, due to the poor flowability we developed powder mixtures containing silicon dioxide as a glidant ${ }^{[23,24]}$. Aiming to prepare the tablets by a simple direct compression microcrystalline cellulose type Avicel PH 102 was used as a binder. Cross-linked sodium carboxymethylcellulose (croscarmellose) was used as disintegration agent and magnesium stearate like lubricant. Determination of the angle of repose of the developed powder mixtures showed remarkable

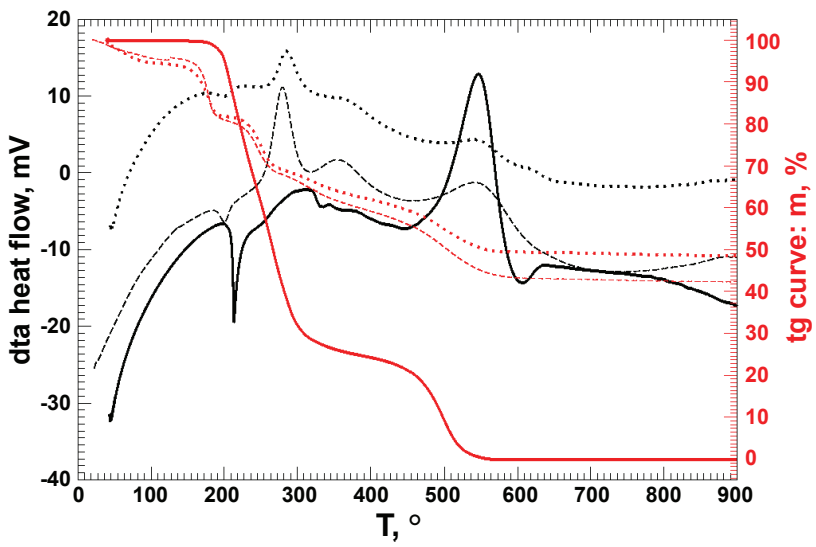

Fig. 4: DTA curves and heat flow curves

DTA curves and heat flow curves of pure glimepiride compared to glimepiride-loaded MCM-41 and HMS samples; (-), (-) glimepiride; (...), (...) HMS+glimepiride; (---), (---) MCM41+glimepiride 
TABLE 2: CHARACTERISTICS OF PURE GLIMEPIRIDE, GLIMEPIRIDE-LOADED MESOPOROUS SILICA PARTICLES AND THE DEVELOPED POWDER MIXTURES

\begin{tabular}{lcccccc}
\hline & Glimepiride & $\begin{array}{c}\text { Glimepiride } \\
\text { +excipients }\end{array}$ & $\begin{array}{c}\text { MCM/ } \\
\text { glimepiride }\end{array}$ & $\begin{array}{c}\text { MCM/glimepiride } \\
\text { +excipients }\end{array}$ & $\begin{array}{c}\text { HMS/ } \\
\text { glimepiride }\end{array}$ & $\begin{array}{c}\text { HMS/ } \\
\text { glimepiride+excipients }\end{array}$ \\
\hline Angle of repose & $52 \pm 5$ & $34 \pm 3$ & $50 \pm 4$ & $32 \pm 3$ & $51 \pm 4$ & $32 \pm 2$ \\
Hausner ratio & $1.41 \pm 0.3$ & $1.18 \pm 0.2$ & $1.36 \pm 0.2$ & $1.13 \pm 0.3$ & $1.36 \pm 0.3$ & $1.13 \pm 0.2$ \\
\hline
\end{tabular}

Mean $\pm S D, n=3$

decrease of the angle. Similarly, the values of Hausner ratio decreased to 1.12-1.18 suggesting an improved flowability ${ }^{[25]}$. The results obtained by calculation of Carr index (fig. 5) showed poor compressibility of pure glimepiride and the loaded mesoporous particles and good compressibility of the mixtures containing the excipients. The achievement of good flowability and compressibility allowed direct compression of the mixtures. The resulted tablets were evaluated for mass uniformity. The deviation from the average mass of 20 tablets between 80 and $250 \mathrm{mg}$ should be $\pm 7.5 \%$ for 18 tablets and $\pm 15 \%$ for two tablets (European Pharmacopeia). The developed tablets passed the test for the mass uniformity. The crushing strength of the tablets varied between 50 and $60 \mathrm{~N}$. Friability of the tablet formulations indicated good resistance of the tablets during further handling and storage (Table 3). A maximum weight loss obtained from the mean of three tests was not more than $1.0 \%$, which fulfilled the requirement of European Pharmacopeia.

In vitro release studies were performed in phosphate buffer with a pH-value of 6.8 (fig. 6). The results showed a remarkable difference between release profiles of tablets containing pure glimepiride, MCM/ glimepiride and HMS/glimepiride particles. Tablets with pure glimepiride showed dissolution of $30 \%$ for two hours. Glimepiride released from tablets prepared with MCM and HMS-loaded particles showed 100 and $93 \%$, respectively. Tablets, containing HMS-loaded particles showed slower release rate most likely due to the hollow core of HMS, associated with higher possibility for recrystallization. The initial burst release of glimepiride attributed to the presence of glimepiride in the external part of the pores of loaded particles, which allows a certain amount of glimepiride to be released quickly. In our opinion, the improvement of the dissolution rate of tablets containing encapsulated glimepiride was due to amorphization of the drug in mesoporous carriers ${ }^{[26]}$. Similar amorphization and improvement of dissolution profile of glimepiride was reported for formulation of solid dispersions of glimepiride and their consequent tableting ${ }^{[27]}$. The theory of homogeneous nucleation claims that crystal

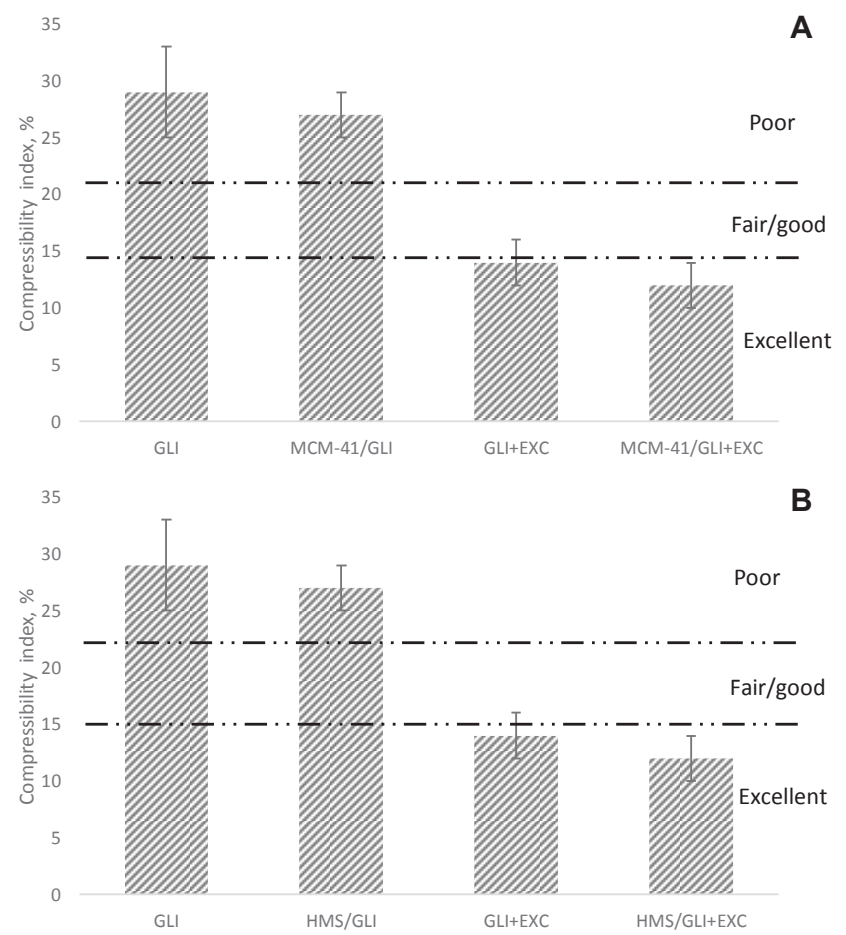

Fig. 5: Compressibility index of powders Compressibility index of powders containing pure and encapsulated glimepiride before and after the addition of excipients. A: MCM-41-loaded and B: HMS-loaded, mean \pm SD, $\mathbf{n}=\mathbf{3}$

TABLE 3: CHARACTERISTICS OF TABLETS

\begin{tabular}{lcc}
\hline & MCM/glimepiride & HMS/glimepiride \\
\hline Hardness (N) & $58 \pm 8 \mathrm{~N}$ & $57 \pm 6 \mathrm{~N}$ \\
Friability (\%) & $0.5 \pm 0.01 \%$ & $0.4 \pm 0.02 \%$ \\
Disintegration (min) & $4 \pm 0.2 \mathrm{~min}$ & $5 \pm 0.3 \mathrm{~min}$ \\
\hline
\end{tabular}

Mean $\pm S D, n=3$

growth occurs spontaneously when a critical size of the nucleus is reached. If the groups of molecules are spatially restricted before reaching a critical nucleation size, growth will be prevented and the drug will exist in a non-crystalline state. In the pores of MSM-41, nucleation occurs in the confined space, which prevents the critical mass from reaching the nuclei, and the drug substance is preserved in an amorphous state. Based on the reduction in free energy of Gibbs, this type of amorphous system is physically stable.

In the present study, tablets containing glimepirideloaded mesoporous silica MCM-41 and HMS were 


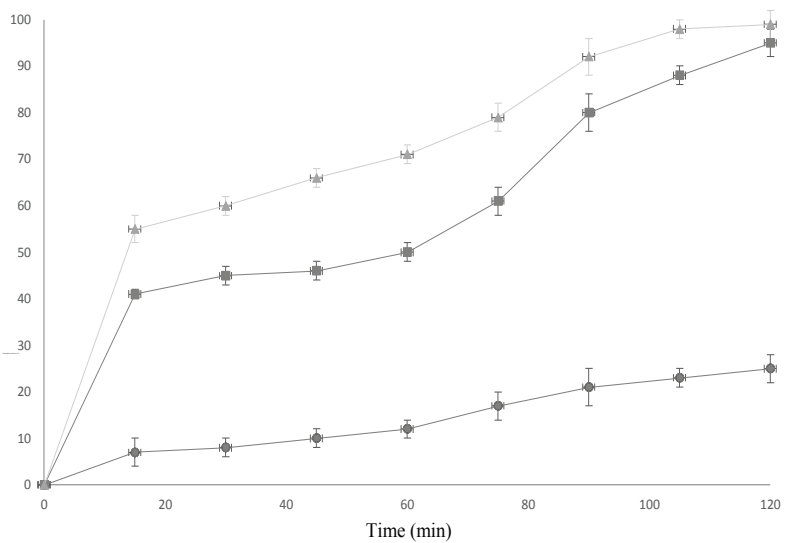

Fig. 6: Dissolution of tablets containing glimepiride, MSM/ glimepiride and HMS/glimepiride

Dissolution profiles of tablets containing glimepiride, MSM/ glimepiride and HMS/glimepiride in phosphate buffer with pH=6.8. ( $(-)$ Glimepiride; ( $-\square$ HMS/glimepiride; $(-\Delta-) \mathrm{MSM} /$ glimepiride, mean $\pm \mathrm{SD}, \mathrm{n}=3$

prepared successfully. Further, the tablets formulated with the encapsulated glimepiride showed markedly improved dissolution compared to tablets prepared with non-encapsulated glimepiride.

\section{REFERENCES}

1. Kouichi I, Masaki W, Youhei N, Takahiro S, Nobuki T, Masahiko T, et al. Efficacy of glimepiride in Japanese type 2 diabetic subjects. Diab Res Clin Pract 2005;68:250-7.

2. Vidyadhara S, Babu JR, Sasidhar RLC, Ramu A, Prasad SS, Tejasree M. Formulation and evaluation of glimepiride solid dispersions and their tablet formulations for enhanced bioavailability. Int J Adv Pharm Sci 2011;2(1):15-20.

3. Yu LX, Amidon GL, Polli JE, Zhao H, Mehta MU, Conner DP, et al. Biopharmaceutics classification system: the scientific basis for biowaiver extensions. Pharm Res 2002;19(7):921-5.

4. Frick A, Möller H, Wirbitzki E. Biopharmaceutical characterization of oral immediate release drug products. In vitro/in vivo comparison of phenoxymethylpenicillin potassium, glimepiride and levofloxacin. Eur J Pharm Biopharm 1998;46(3):305-11.

5. Massi-Benedetti M. Glimepiride in type 2 diabetes mellitus: a review of the worldwide therapeutic experience. Clin Ther 2003;25:799-816.

6. Ammar HO, Salama HA, Ghorab M, Mahmoud AA. Formulation and biological evaluation of glimepiridecyclodextrin-polymer systems. Int J Pharm 2006;309:129-38.

7. Rouquerol J, Avnir D, Fairbridge CW, Everett DH, Haynes JM, Pernicone N. Recommendations for the characterization of porous solids. Pure Appl Chem 1994;66:1739-58.

8. Zhang Y, Wang J, Bai X, Jiang T, Zhang Q, Wang S. Mesoporous silica nanoparticles for increasing the oral bioavailability and permeation of poorly water-soluble drugs. Mol Pharm 2012;9:505-13.

9. Boregowda SS, Rao BPR, Jayarama RA, Guruchar NLV. Application of water-soluble/dispersible polymeric carriers in drug dissolution modulation. Asian J Pharm Sci 2011;6(1):26-35.

10. Kiran T, Shastri N, Ramakrishna S, Sadanandam M. Surface solid dispersion of glimipiride for enhancement of dissolution rate. Int J PharmTech Res 2009;1(3):822-31.
11. Reven S, Grdadolnik J, Kristl J, Zagar E. Hyperbranched poly(esteramides) as solubility enhancers for poorly watersoluble drug glimepiride. Int J Pharm 2010;396(1-2):119-26.

12. Zhang Y, Zhi Z, Jiang T, Zhang J, Wang Z, Wang S. Spherical mesoporous silica nanoparticles for loading and release of the poorly water-soluble drug telmisartan. J Control Release 2010;145:257-63.

13. Beňová $\mathrm{E}$, Zeleňák $\mathrm{V}$, Halamová $\mathrm{D}$, Almáši $\mathrm{M}$, Petrul'Ová $\mathrm{V}$, Psotka M, et al. A drug delivery system based on switchable photo-controlled p-coumaric acid derivatives anchored on mesoporous silica. J Mater Chem B 2017;5:817-25.

14. Rahikkala A, Rosenholm JM, Santos HA. Biofunctionalized Mesoporous Silica Nanomaterials for Targeted Drug Delivery. Biomedical Applications of Functionalized Nanomaterials. In: Sarmento B, Neves JD, editors. Biomedical Applications of Functionalized Nanomaterials. Amsterdam, Netherlands: Elsevier; 2018. p. 489-20.

15. Zhang Y, Jiang T, Zhang Q, Wang S. Inclusion of telmisartan in mesocellular foam nanoparticles: drug loading and release property. Eur J Pharm Biopharm 2010;76:17-23.

16. Van Speybroeck M, Barillaro V, Thi TD, Mellaerts R, Martens J, Humbeeck JV. Ordered mesoporous silica material SBA15: a broad-spectrum formulation platform for poorly soluble drugs. J Pharm Sci 2009;98(8):2648-58.

17. Tzankov B, Yoncheva K, Popova M, Szegedi A, Momekov $\mathrm{G}$, Mihaly J, Lambov N. Indometacin loading and in vitro release properties from novel carbopol coated spherical mesoporous silica nanoparticles. Microporous Mesoporous Mater 2013;171:131-38.

18. Flanigen EM, Khatami H, Szymanski HA. Infrared structural studies on zeolite frameworks. Adv Chem 1971;101:201-28.

19. Zhu Y, Fang Y, Borchardt L, Kaskel S. PEGylated hollow mesoporous silica nanoparticles as potential drug delivery vehicles. Microporous Mesoporous Mater 2011;141:199-206.

20. Ambrogi V, Perioli L, Marmottini F, Moretti M, Lollini E, Rossi C. Chlorhexidine MCM-41 mucoadhesive tablets for topical use. J Pharm Innov 2009;4(4):156-64.

21. Xu WJ, Gao Q, Xu Y, Wu D, Sun YH. pH-controlled drug release from mesoporous silica tablets coated with hydroxypropyl methylcellulose phthalate. Mater Res Bull 2009;44(3):606-12.

22. Carr RL. Evaluating Flow Properties of Solids. Chem Eng 1965;72:163-68.

23. Technical Data Sheet, Properties of CAB-O-SIL ${ }^{\circledR}$ M-5P Fumed Silica. Cabot Corporation 1995. Available from: http:// www.cabotcorp.com/ /media/files/brochures/fumed-metaloxides/brochure-cab-o-sil-fumed-silica-pharmaceuticalnutraceutical-apps.pdf.

24. Technical Data Sheet, Influence of CAB-O-SIL ${ }^{\circledR}$ M-5P on the Angle of Repose and Flow Rates of Pharmaceutical Powders. Cabot Corporation 2005. Available from: https://www.yumpu. com/en/document/read/6632855/influence-of-cab-o-silr-m5 p-on-the-angle-of-repose-and-flow-.

25. Hausner H. Friction conditions in a mass of metal powder. Int J Powder Metall 1967;3:7-13.

26. Popova M, Szegedi A, Mavrodinova V, Tušar NN, Mihály $\mathrm{J}$, Klébert S. Preparation of resveratrol-loaded nanoporous silica materials with different structures. J Solid State Chem 2014;219:37-42.

27. Ning X, Sun J, Han X, Wu Y, Yan Z, Han J. Strategies to improve dissolution and oral absorption of glimepiride tablets: solid dispersion versus micronization techniques. Drug Dev Ind Pharm 2011;37(6):727-36. 